\title{
Study on the Efficiency Evaluation of Taoyuan Pond
}

\author{
Wenping Shieh ${ }^{1}$, Wenling Shieh ${ }^{2}$ and Wenchin $\operatorname{Lin}^{3}$ \\ ${ }^{1}$ Doctorate student of Department of Civil Engineering, Chung Hua University, Taiwan \\ ${ }^{2}$ Nanya Institute of Technology, Taiwan \\ ${ }^{3}$ Chung Hua University, Taiwan
}

Keywords: Ponds, efficiency, data envelopment analysis.

\begin{abstract}
Ponds possess unique landscapes at Taoyuan terrain, the number of these man-made ponds with irrigation function of having to build a pond, in recent years, are continuously decreasing, the cover areas are also shrinking. This study aims to establish a complete set of ponds operating performance evaluation model to assess operational performance of the various categories ponds. First, to establish general evaluation criteria in accordance with the conditions inherent in the various ponds. Finally, Data Envelopment Analysis (DEA) model is applied to study the operational efficiency of the various categories of ponds. According to the results of operational efficiency of different categories, we present the improvement recommendations for inefficient pond categories. In this study, we studied the fifty five ponds infused from the first to fourth branch of Taoyuan irrigation system as our study objectives to verify the feasibility and correctness of the proposed ponds performance evaluation model.
\end{abstract}

\section{Introduction}

In the agricultural era, the pond is an important source of irrigation water for farmers. For the purpose of cultivating this meadow to produce luscious harvest of crops, it is crucial to maintain reliable and stable sources of irrigation water. The pond plays an important role in the agricultural society. Everything in the pond is a versatile resource that can generate considerable socioeconomic value (Turner et al., 2000).

The reason why Taoyuan has been known as "Thousand Pond Township", is because it has a landscape that is densely covered with numerous ponds on the ground of its terrain. In recent years, the impact of various factors to ponds, such as regional industrialization, urbanization and the reduction of a large number of surrounding arable land has leaded gradually pond's original function to fade. Many ponds were earth-filled to become a land of other purposes. The number of ponds are, now, reducing rapidly, throwing the ponds of Taoyuan into crisis.

The scope of this study is a total of 55 existing ponds, where the water are released from the first branch stream to the fourth branch stream in Taouan. In this study, we aims to perform research analysis with economic indicator, which is Data Envelopment Analysis (Data Envelopment Analysis, referred to as DEA), in terms of operation efficiency for each pond.

\section{Literature Review}

The literatures in relation to the assessment of the efficiency of pond are far and few in Taiwan, we decided to utilize the approach of efficiency assessment in wetland, the scope of assessment or the assessment model based on the research literatures that were published worldwide.

Shu-mei Yu (2009) pointed out that "monitoring" and "assessment" of wetlands are the foundation for environmental management. That the selected appropriate procedure or method for the efficiency assessment were based on the objectives of the pond wetland assessment, the model of the pond wetland, the model alternatives, government policies and regulations applicable to the objectives. The above methods are mostly about habitat function evaluation, but there are few researches on the evaluation of wetland habitat in Taiwan, such as Soil and Water Characteristic Analysis and 
Ecological Risk Assessment of Kuan-Du Wetland, and the relevant investigation and evaluation of soil and water quality of wetland. Shi-Hua Yang (2007) created an efficiency analytical model for Irrigation Association using Data envelopment Analysis (DEA). Wei-Hung Yeh (2010) adopted CCR and $\mathrm{BCC}$ models of DEA to evaluate the environmental management performance for water treatment facilities along river bank including the relative efficiency, the purely technical efficiency, the scale efficiency and the evaluation of returns to scale. Moreover, it explored the relationship between decontamination and business performance utilizing slack variables and sensitive analysis. Based on the analysis of the data extracted and quantified from 19 artificial wetlands. Lin Yu-jie (2005) evaluated the relative efficiency of man-made wetlands using the quantitative data envelopment analysis method, and established a benchmark for other wetlands in order to conduct the further improvements.

\section{Methodology}

This study analyzed the operational performance of 55 ponds in Taoyuan, which is connected with the first, second, third and fourth branch of Taoyuan irrigation system based upon the four categories of operational management functions. Based upon their functional categorization, there are 18 ponds that were clustered for the function of agriculture irrigation cluster, 11 ponds for the function of water supply cluster, 16 ponds for the funtion of ecological protection cluster, and 10 for flood detention and drainage cluster. By using the DEA method to evaluate the operation efficiency of ponds of Taoyuan, the CCR model proposed by Charnes et al. was used to obtain the relative efficiency of Decision Making Unit (DMU), and acquired the slack variables for the direction of efficiency improvement. Following that, BBC model proposed by Banker et al. was employed to acquire the DMU's technical efficiency and scale efficiency.

In the DEA model establishment and application process, they are equal important to be in line with the purpose of efficiency improvement for the ponds when selecting an evaluation model, which is DEA, and selecting appropriate measurement variables. It could distort the assessment results or lose the weight of the representative in case of choosing inappropriate DEA mode or measurement variables.

We took into account the goals of the pond management team to establish appropriate assessment criteria when selecting the variables for input and output. The selected input variables consist of: Water area space, water consumption (agricultural water consumption, industrial water consumption, residential water consumption and public water consumption), pond and water flow system maintenance expense (construction costs, operation and maintenance costs, electricity, staff costs, sludge removal fees, environmental maintenance costs, equipment maintenance costs, monitoring fees). The selected output variables include: agricultural \& non-agricultural production value, biodiversity, pond water condition and flood detention and drainage.

\section{Data analysis}

The first step in choosing input and output is that the input and output must comprise multi-collinearity and isotonicity diagnoses. All of the inputs and outputs require appropriate and positive correlation coefficients, and input and output must accord with the isotonicity (Bowlin, 1987). That is to say the output items should reduce or remain stable in the situation of an increase in input items. We calculated the Pearson correlation coefficient was utilized to analyze the level of consistency and their directions between the selected variables of inputs and outputs. Table 1 demonstrates that all the correlation coefficients are positive and sound ( $p$-value $<0.05$ ), which refers to all the input variables and output variables are appropriate to conduct further analysis. We, then, employs BCC-DEA to envelop the technical efficiency of the selected 55 ponds in Taoyuan County. The DEA model basically represents the most suitable programming weights or the observation value of efficiencies between output and input items for different DMUs (Chen and Yu, 1997). For those 
DMUs that were evaluated as lacking of technical efficiency, we conducted slack value analysis between the input and output indicators. Finally, the sensitivity analysis of the agricultural pond cluster, non-agricultural water supply pond clusters, and ecological pond cluster. The sensitivity analysis was performed using the stepwise regression with the input and output items being increased (or decreased) step by step, while changes in the efficiency value are overlooked, with the change of situation being used to select methods of assessing input and output (Charnes et al. , 1985). Once the calculation of the following inputs, output variables is complete, we used of program Excel Slover as our solution software to develop efficiency analysis.

Table 1. Pearson correlation coefficient between inputs and outputs

\begin{tabular}{|c|c|c|c|c|c|c|c|}
\hline Variable & $\mathrm{I} 1$ & $\mathrm{I} 2$ & $\mathrm{I} 3$ & $\mathrm{O} 1$ & $\mathrm{O} 2$ & $\mathrm{O} 3$ & $\mathrm{O} 4$ \\
\hline $\mathrm{I} 1$ & 1 & $0.345^{*}$ & $0.561^{* *}$ & $0.278^{*}$ & $0.407^{*}$ & $0.623^{* * *}$ & $0.788^{* * *}$ \\
\hline $\mathrm{I} 2$ & & 1 & $0.462^{*}$ & $0.363^{*}$ & $0.473^{* *}$ & $0.448^{*}$ & $0.384^{*}$ \\
\hline $\mathrm{I} 3$ & & & 1 & $0.593^{* *}$ & $0.267^{*}$ & $0.523^{* *}$ & $0.274^{*}$ \\
\hline O1 & & & & 1 & $0.415^{* *}$ & $0.205^{*}$ & $0.368^{*}$ \\
\hline O2 & & & & & 1 & $0.337^{*}$ & $0.226^{*}$ \\
\hline O3 & & & & & & 1 & $0.482^{* *}$ \\
\hline O4 & & & & & & & 1 \\
\hline
\end{tabular}

Note $: * * *, * * \& *$, indicate $1 \%, 5 \% \& 10 \%$ significant level; $\mathrm{I} 1=$ water area space, $\mathrm{I} 2=$ water consumption, $\mathrm{I} 3=$ pond and water flow system maintenance expense; $\mathrm{O} 1=$ agricultural non agricultural production value, $\mathrm{O} 2=$ biodiversity, $\mathrm{O} 3=$ pond water condition, $\mathrm{O} 4=$ flood detention and drainage.

\section{Research result}

Agricultural pond cluster

Altogether, there are 18 ponds to be assessed in the agricultural pond cluster. Through the efficiency analysis with DEA, the reasons for the lack of efficiencies were identified. They were mainly because lacking of scale efficiency and the inputs that are related to management functions were less than the optimum scale production. From the output perspective, the overall performance remain to be upgraded and improved, in particular, for the variable of the pond water conditions. Moreover, the variables of water consumption and water flow system maintenance expense are relatively more important. It's crucial to strength a better implementation of both two management functions, which should conduct better allocations for water consumption, tightly control on maintenance expense, improve water quality conditions and remove pollution.

Water supply pond cluster

For the 11 ponds to be assessed in the water supply pond cluster. Through the efficiency analysis with DEA, The pure technical efficiency value was equal to 1 or approaches 1 . The reasons for the lack of efficiencies were also identified: They were because input of this cluster was proceeding in less than optimal scale, which indicated that input were not in the optimized scale. From the output perspective, agricultural \& non-agricultural production value, biodiversity, pond water condition and flood detention and drainage are the performance indicators that remain to be upgraded and improved, in particular, for the variable of the pond water conditions. In view of the functional aspects of pond, the "Water area space" and the "water flow system maintenance expense" are the most important items. Therefore, it's very essential to beef up two management functions in terms of increasing the efficiency of water supply pond cluster.

Ecological pond cluster

There are 16 ponds to be assessed in the ecological pond cluster. The reasons for the lack of efficiencies were also identified: They were because input of this cluster was proceeding in the status of Increased returns to scale, which indicated that input were not in the optimized scale. From the output perspective, agricultural \& non-agricultural production value, biodiversity, pond water condition and flood detention and drainage are the performance indicators that remain to be upgraded 
and improved, in particular, for the variables of the agricultural \& non-agricultural production value and the pond water conditions.

Flood detention and drainage cluster

For the 10 ponds to be assessed in the flood detention and drainage pond cluster. Through the efficiency analysis with DEA, The pure technical efficiency value was equal to 1 or approaches 1 . The reasons for the lack of efficiencies were also identified: They also were validated as the input of this cluster was proceeding in less than optimal scale, which indicated that input were not in the optimized scale, in particular, in the variable of the water area space. From the output perspective, agricultural \& non-agricultural production value, biodiversity, pond water condition and flood detention and drainage are the performance indicators that all remain to be upgraded and improved, in particular, for the variable of the flood detention and drainage. In view of the functional aspects of pond, the "Water area space" and the "water flow system maintenance expense" are the most important items.

\section{Conclusion}

In this study, 55 ponds were clustered according to their attributes, and their relative operational efficiencies were also analyzed based on the relationship between management function and their performance for each pond. According to the attributes of the four functional pond clusters and the analysis results using DEA, the advantages and disadvantages for various functional ponds are also found and identified.Therefore, this study provides a clear direction and the anticipated tasks to be accomplished in order to improve the operational efficiencies for the ponds in Taoyuan County. According to past scholarly research, they have been pointed out that there are still substantial room for improvements in overall input management of ponds. Moreover, the improvement of production management function is significantly greater than that of human resource management and marketing management function on total factor productivity. Another scholar has measured the performance of the four categories of human resources management in domestic, and found that the performance of the agricultural pond is the weakest the results are also consistent with the improvement direction proposed in this paper.

\section{References}

[1] Yu-Jie Lin. Quantitative Evaluation of Pollutants Treatment and Economical Efficiency for Man-Made Wetlands, M.S. thesis, Graduate Institute of Science Education and Environmental Education, National Kaohsiung Normal University, Taiwan (2005).

[2] Shu-mei Yu. Coastal Wetland Monitoring and Evaluation with Multitemporal Remote Sensing Images, M.S. thesis, Department of Earth Sciences, National Cheng Kung University, Taiwan (2009).

[3] Shi-Hua Yang. A Comparative Study of the Operational Efficiency of Taiwan Irrigation Associations - The Application of 3-Stage DEA and Metafrontier Models, Ph.D. thesis, Department of Agricultural Economics, National Taiwan University, Taiwan (2007).

[4] Wei-Hung Yeh. Environmental Management Performance Evaluation of On-site Water Treatment Facility by the Riverside - An Application of Data Envelopment Analysis. M.S. thesis, Institute of Natural Resource Management, National Taipei University, Taiwan (2010).

[5] Bartoldus, C.C. "A comprehensive review of wetland assessment procedures: a guide for wetland practitioners", Environmental Concern Inc., MD (1999a).

[6] Bowlin, W.F., "Evaluating the efficiency of US Air Force real-property maintenance activities", Journal of the Operational Research Society, Vol. 38 No. 2 (1987), pp. 127-35.

[7] Chen, T.Y. and Yu, O.S., "Performance evaluation of selected US utility commercial lighting demand side management programs", Energy Engineering, Vol. 94 No. 4 (1997), pp. 50-66. 
[8] Tuner, R. K., Jeroen C. J. M., Bergh, V.D., Söderqvist, T., Barendregt, A., Straaten, J.V.D., Maltby, E., and Ierland E.V. "Ecological-economic analysis of wetlands: scientific integration for management and policy", Ecological Economics, No. 35 (2000), pp. 7-23. 